\title{
Is routine antenatal venereal disease research laboratory test still justified? Nigerian experience
}

This article was published in the following Dove Press journal:

International Journal of Women's Health

7 January 2015

Number of times this article has been viewed

\author{
Betrand O Nwosu' \\ George U Eleje' \\ Amaka L Obi-Nwosu ${ }^{2}$ \\ Ita F Ahiarakwem ${ }^{3}$ \\ Comfort N Akujobi ${ }^{4}$ \\ Chukwudi C Egwuatu ${ }^{4}$ \\ Chukwudumebi O C \\ Onyiuke ${ }^{5}$ \\ 'Department of Obstetrics and \\ Gynecology, Nnamdi Azikiwe \\ University, Nnewi Campus, Nnewi, \\ Anambra State, Nigeria; ${ }^{2}$ Department \\ of Family Medicine, Nnamdi Azikiwe \\ University Teaching Hospital, Nnewi, \\ Nigeria; ${ }^{3}$ Department of Medical \\ Microbiology, Imo State University \\ Teaching Hospital, Orlu, Imo State, \\ Nigeria; ${ }^{4}$ Department of Medical \\ Microbiology, Nnamdi Azikiwe \\ University, Nnewi Campus, Nnewi, \\ Anambra State, Nigeria; ${ }^{5}$ Department \\ of Medical Microbiology, Nnamdi \\ Azikiwe University Teaching Hospital, \\ Nnewi, Anambra State, Nigeria
}

Correspondence: George U Eleje Department of Obstetrics and Gynaecology, Nnamdi Azikiwe University, Nnewi Campus, PMB 5025,

Nnewi, Anambra State, Nigeria

Tel +2 3480 68I I 7444

Email georgel21@yahoo.com
Objective: To determine the seroreactivity of pregnant women to syphilis in order to justify the need for routine antenatal syphilis screening.

Methods: A multicenter retrospective analysis of routine antenatal venereal disease research laboratory (VDRL) test results between 1 September 2010 and 31 August 2012 at three specialist care hospitals in south-east Nigeria was done. A reactive VDRL result is subjected for confirmation using Treponema pallidum hemagglutination assay test. Analysis was by Epi Info 2008 version 3.5.1 and Stata/IC version 10.

Results: Adequate records were available regarding 2,156 patients and were thus reviewed. The mean age of the women was 27.4 years $( \pm 3.34)$, and mean gestational age was 26.4 weeks ( \pm 6.36$)$. Only 15 cases $(0.70 \%)$ were seropositive to VDRL. Confirmatory T. pallidum hemagglutination assay was positive in 4 of the 15 cases, giving an overall prevalence of $0.19 \%$ and a false-positive rate of $73.3 \%$. There was no significant difference in the prevalence of syphilis in relation to maternal age and parity $(P>0.05)$.

Conclusion: While the prevalence of syphilis is extremely low in the antenatal care population at the three specialist care hospitals in south-east Nigeria, false-positive rate is high and prevalence did not significantly vary with maternal age or parity. Because syphilis is still a serious but preventable and curable disease, screening with VDRL alone, without confirmatory tests may not be justified. Because of the increase in the demand for evidence-based medicine and litigation encountered in medical practice, we may advocate that confirmatory test for syphilis is introduced in routine antenatal testing to reduce the problem of false positives. The government should increase the health budget that will include free routine antenatal testing including the T. pallidum hemagglutination assay.

Keywords: VDRL tests, treponema screening, antenatal care, congenital syphilis management

\section{Introduction}

Antepartal and peripartal transmission of Treponema pallidum, the causative agent of syphilis, leads to severe consequences for newborns. ${ }^{1,2}$ Active syphilis in a pregnant woman is a crippling disease and may cause spontaneous abortion, stillbirth, or congenital syphilis. When the neonate is affected, clinical symptoms may manifest at birth or develop during childhood. Serological tests for syphilis are therefore often routinely performed early in pregnancy. ${ }^{3-6}$ The seropositive rate among pregnant women reported in Nigeria over a 40 -year period has been put between $0.6 \%$ and $2.3 \%,{ }^{5-7}$ while generally in Africa, the figure is in the range of $3 \%-18 \%{ }^{8-10}$

The importance of pregnancy screening for syphilis in a country with limited health care resources must be weighed against other requirements. Thus, the occurrence of syphilis during pregnancy, availability of laboratory, and the possibility of treating 
infected women adequately must be considered from a costbenefit point of view when deciding whether to include routine serological screening for syphilis in a national maternal health care program.

While syphilis during pregnancy in the Western world today is rare ${ }^{11,12}$ largely due to effective antenatal screening, maternal syphilis remains an increasing problem in many countries of sub-Saharan Africa. ${ }^{8,10}$ Because there is no national policy for antenatal screening in Nigeria, there appears to be no consensus among obstetricians in Nigerian hospitals on the need for routine antenatal screening. ${ }^{10}$

Most individuals with syphilis are asymptomatic or have transient lesions, and so serological tests are often the preferred method for detection. ${ }^{13-15}$ Simple and cheap rapid plasma reagin (RPR) or venereal disease research laboratory (VDRL) tests that detect cardiolipin antibodies, which are found in cases of acute or recent syphilis, are used for screening and diagnosis. However, these tests are not specific for T. pallidum and are referred to as nonspecific treponemal tests. They can lead to false-positive diagnoses in pregnant women and unnecessary treatment. ${ }^{3,15}$

As a second step, non-treponemal tests should be confirmed with tests that can detect Treponema-specific antigens such as the T. pallidum hemagglutination assay (TPHA) or T. pallidum particle-agglutination assay. ${ }^{12,13}$ These specific tests are not widely available in developing countries because they are laboratory dependent and require trained personnel, refrigeration for storage of reagents, and electricity to run its equipment. ${ }^{13-15}$ Test results are only available days or weeks later, and specimens could be lost in the process of transportation. Furthermore, some patients may not return for or get their results in time for treatment. This may lead to adverse clinical outcomes, continued transmission of infection, and waste of health care resources. ${ }^{13,14}$

In Nigeria, the financial resources spent in doing the routine VDRL may be extended for the determination of hepatitis B surface antigen and hepatitis C antibody, which are not yet routine investigations in Nigerian hospitals. Again, the major objective of the National Health Insurance Scheme in Nigeria is to protect families from the financial hardship of large medical bills, the Nigeria national health care budget is less than $12.5 \%$ of the total budget and routine antenatal testing is not free and health insurance coverage is poor, because up to $95 \%$ of the population who are in need of financial risk protection against ill-health are yet to be covered by the scheme. ${ }^{16,17}$

Although, there have been previous studies in Nigeria that have questioned the continuation of antenatal VDRL test, all of which are more than a decade old, none is multicenter in design. ${ }^{18,19}$ Expectedly, a lot may have changed in the pattern of transmission. Therefore, the aim of this cross-sectional study was to determine the seroreactivity of pregnant women to syphilis in three south-east Nigerian specialist care hospitals in order to justify the need for routine antenatal syphilis screening in Nigeria.

\section{Methods}

This is a two-year retrospective analysis of VDRL results of pregnant women who attended the antenatal clinic of Nnamdi Azikiwe University Teaching Hospital, Nnewi; Chimex Specialist Hospital, Nnewi; and Imo State University Teaching Hospital, Orlu, all in south-east Nigeria from September 2010 to August 2012. Nnamdi Azikiwe University Teaching Hospital and Imo State University Teaching Hospital are tertiary hospitals, while Chimex Specialist Hospital is a private secondary health care facility. Booking registers and VDRL registers were obtained from the medical records department and the hospital laboratory. All antenatal attendees who had VDRL serology test for syphilis were analyzed.

Data were collected by means of a prepared proforma. These data included selected demographic and obstetrics information. Information on the result for screening for syphilis was also extracted including confirmatory test and treatment given. Women with incomplete data were excluded from the study. Ethical clearance was obtained from the research ethics committee of Nnamdi Azikiwe University Teaching Hospital institutional ethical review committee. Permission was sought from the management of the hospitals.

All serum samples, test antigens, and control samples were brought to room temperature $\left(26^{\circ} \mathrm{C}\right)$ and tested using the VDRL test kit (Fich-Tech Diagnostics Inc, Chino, CA, USA). The TPHA test was used as a confirmatory test for all positive VDRL sera.

Data were summarized as means \pm standard deviation, percentages, and mode. Data entry and analysis was done using Epi Info 2008 (version 3.5.1; Epi Info, Centers for Disease Control and Prevention, Atlanta, GA, USA) and Stata/IC software version 10. Comparative analysis was performed using Student's $t$-test and/or chi-square test where applicable. A $P$-value $<0.05$ was taken as significant.

\section{Results}

During the study period, 2,156 of 2,167 (99.5\%) women had adequate records and were subsequently reviewed. 
Patients were included when the newly registered pregnant women attended the antenatal clinics of Nnamdi Azikiwe University Teaching Hospital, Nnewi; Chimex Specialist Hospital, Nnewi; and Imo State University Teaching Hospital, Orlu, all in south-east Nigeria between September 2010 and August 2012 were studied.

All of the 2,156 women underwent VDRL screening. The age range was 20-47 years (mean age of the women was $27.4 \pm 3.34$ years), and the modal parity was 0 . Up to $941(43.6 \%)$ patients were nulliparous and 1,215 (56.4\%) were parous.

However, 773 (35.9\%) were screened in the first trimester, 1,246 (57.8\%) in the second trimester, and $137(6.3 \%)$ in the third trimester (Table 1). The mean gestational age at screening was $23.4 \pm 6.36$ weeks, and the majority of women $(93.7 \%)$ registered for their pregnancies within the first and second trimesters of pregnancy.

Only 15 cases $(0.70 \%)$ were seropositive for the syphilis antibody (positive VDRL). Confirmatory TPHA were positive (active syphilis) in 4 of the 15 cases, giving an overall prevalence of $0.19 \%$ (Table 2 ). In all, $73.33 \%$ $(11 / 15)$ of all VDRL-positive women corresponding to $0.51 \%$ of all women used in the study were biological false positives. The relationship between maternal age and parity of the patients with the seroreactivity of syphilis is shown in Table 3. There was no significant difference in the prevalence of syphilis in relation to maternal age and parity $(P>0.05)$.

Of the women with active syphilis, one was in the first trimester and two each in the second trimester and third trimester. They all received a single-dose intramuscular injection of benzathine penicillin 2.4 MU except one woman, who received erythromycin.

Table I Parameters of pregnant women attending antenatal clinics of three specialist care hospitals in south-east Nigeria

\begin{tabular}{lllll}
\hline & NAUTH & CHIMEX & IMSUTH & Totals (\%) \\
\hline No of women & 849 & 458 & 849 & 2,156 \\
Age (years) & $18-45$ & $20-43$ & $19-47$ & $18-47$ \\
$\begin{array}{l}\text { Mean age } \\
\text { (years) }\end{array}$ & $29.8 \pm 4.1$ & $26.3 \pm 9.0$ & $27.7 \pm 6.2$ & $27.4 \pm 3.3$ \\
$\begin{array}{l}\text { Parity } \\
\text { Nulliparous }\end{array}$ & 368 & 262 & 311 & $941(43.6 \%)$ \\
Parous & 811 & 196 & 538 & $1,215(56.4 \%)$ \\
$\begin{array}{l}\text { Trimester } \\
\text { First }\end{array}$ & 279 & 191 & 303 & $773(35.9 \%)$ \\
Second & 521 & 233 & 492 & $1,246(57.8 \%)$ \\
Third & 49 & 34 & 54 & $137(6.3 \%)$ \\
\hline
\end{tabular}

Abbreviations: CHIMEX, Chimex Specialist Hospital, Nnewi; IMSUTH, Imo State University Teaching Hospital, Orlu; NAUTH, Nnamdi Azikiwe University Teaching Hospital, Nnewi.
Table 2 The seroprevalence of syphilis in 2, I56 pregnant women at the antenatal clinics of three specialist care hospitals in southeast Nigeria

\begin{tabular}{llll}
\hline Facility & $\begin{array}{l}\text { VDRL } \\
\text { positive (\%) }\end{array}$ & $\begin{array}{l}\text { TPHA } \\
\text { positive (\%) }\end{array}$ & $\begin{array}{l}\text { TPHA } \\
\text { negative (\%) }\end{array}$ \\
\hline NAUTH (849 patients) & $8(0.94)$ & $\mathrm{I}(0.12)$ & $7(0.82)$ \\
CHIMEX (458 patients) & $\mathrm{I}(0.22)$ & $0(0.00)$ & $\mathrm{I}(0.22)$ \\
IMSUTH (849 patients) & $6(0.70)$ & $3(0.35)$ & $3(0.35)$ \\
Total (2, I56 patients) & $\mathrm{I}(0.70)$ & $4(0.19)$ & $\mathrm{II}(0.5 \mathrm{I})$ \\
\hline
\end{tabular}

Abbreviations: CHIMEX, Chimex Specialist Hospital, Nnewi; IMSUTH, Imo State University Teaching Hospital, Orlu; NAUTH, Nnamdi Azikiwe University Teaching Hospital, Nnewi; TPHA, Treponema pallidum hemagglutination assay; VDRL, venereal disease research laboratory.

\section{Discussion}

The consequences of syphilis in the mother and fetus during pregnancy are considerable, but preventable. Syphilis is a public health problem that can lead to serious consequences for the newborns when not diagnosed or when undertreated. Serological screening must be offered at the first prenatal visit as recommended by Global Elimination of Congenital Syphilis. ${ }^{14}$ Ideally, this screening should be done during the first trimester or at the first antenatal visit of the woman and subsequently early in the third trimester, even in lowprevalence populations. ${ }^{20}$

The seroprevalence of syphilis as measured by VDRL in this study was $0.70 \%$; however, $73.33 \%$ of these were biological false positives. The true seroprevalence, therefore, was $0.19 \%$. This figure is lower than the range of $0.6 \%-2.3 \%$ reported over a 40 -year period in $\mathrm{Nigeria}^{5-7}$ and in other African countries. ${ }^{8-10}$ This is higher than the prevalence of $0.05 \%$ reported in Maiduguri ${ }^{7}$ (northern Nigeria). This implies that the prevalence of syphilis in Nigeria has been on the decline. Similarly, the results of previous study in Enugu on VDRL screening in pregnancy by Ikeme and Okeke $^{21}$ strongly showed a continuing very low prevalence rate of syphilis. Nevertheless, they still supported continued screening of pregnant women in spite of this low prevalence rate, because this will eradicate the effects of undiagnosed

Table 3 Relationship between age and parity with the seroreactivity of syphilis

\begin{tabular}{|c|c|c|c|c|c|}
\hline $\begin{array}{l}\text { Variable } \\
\text { (age) }\end{array}$ & $\begin{array}{l}\text { No of } \\
\text { women }\end{array}$ & $\begin{array}{l}\text { Age } \\
\text { (years) }\end{array}$ & $\begin{array}{l}\text { Mean age } \\
\text { (years) }\end{array}$ & t-test & P-value \\
\hline Seronegative & 2,152 & $18-47$ & $27.2 \pm 3.8$ & -1.3152 & 0.189 \\
\hline Seropositive & 4 & $25-46$ & $29.7 \pm 2.1$ & & \\
\hline $\begin{array}{l}\text { Variable } \\
\text { (parity) }\end{array}$ & $\begin{array}{l}\text { No of } \\
\text { nulliparous }\end{array}$ & $\begin{array}{l}\text { No of } \\
\text { parous }\end{array}$ & $\begin{array}{l}\text { Chi- } \\
\text { square }\end{array}$ & $P$-value & \\
\hline Seronegative & 940 & 1,212 & 1.1387 & 0.413 & \\
\hline Seropositive & I & 3 & & & \\
\hline
\end{tabular}


and untreated syphilis. The low prevalence found in this study may be attributed to less risky sexual behavior in the study group. Interventions to control sexually transmitted infections including introduction of syndromic management of sexually transmitted infection and ease of use of antibiotics may have also contributed to this very low prevalence. ${ }^{22}$

Surprisingly, in a study by Adeleke et $\mathrm{a}^{23}$ on the seroprevalence of malaria, hepatitis $\mathrm{B}$, and syphilis co-triple infections among pregnant women in Osogbo, south-west Nigeria, none of the participants was positive for syphilis. Although, according to the Federal Ministry of Health, ${ }^{24}$ the national prevalence for syphilis among Nigerian pregnant women was estimated as $0.3 \%$, Adeleke et $\mathrm{al}^{23}$ concluded that the zero prevalence of syphilis recorded in their study may indicate extremely low cases of the infection at the study area.

Another noteworthy finding of our data set was that the seroreactivity of syphilis does not vary with the age and parity of the patients $(P>0.05)$. Although this observation needs to be validated using a larger cohort of patients, this finding was similar to that of Adeleke et $\mathrm{al}^{23}$ in Osogbo, Nigeria. It was also corroborated by a previous study by Mbamara and Obiechina ${ }^{25}$ in Onitsha, Nigeria. However, in patients suffering from HIV, lyme disease, pneumonia, and systemic lupus erythematosus, the VDRL test mostly gives a false-positive result. ${ }^{26}$ The high prevalence of HIV/AIDS in our environment may explain the high prevalence of false-positive VDRL test results $(>70 \%)$ in our data set. Being a screening test, false-positive VDRL rates may discourage its use as a routine test assisting in antenatal care; it can make patients select a better evaluation of syphilis. VDRL as a screening test can be used as an initial test for at risk patients so that those positive to VDRL will undergo confirmatory test.

Thus, the VDRL test will help to detect that the person has been infected and not to specifically rule out the current infection. Some authors have hitherto advised a reappraisal of the practice of routine antenatal screening for syphilis having demonstrated low seroprevalence in their antenatal population. ${ }^{27}$ They questioned the cost-effectiveness of this practice given its low yield. ${ }^{27}$ Nevertheless, the VDRL test is cheap to perform but its use of microscopic reading compels an exact laboratory technique. As was used in the present study, the TPHA test may be a good option for qualified laboratories in the developing countries when a confirmatory test is needed. ${ }^{28}$

Majority (93.6\%) of women in this study booked at the first or second trimesters of pregnancy. This implies that early screening and treatment of positive confirmed cases will be effective. This suggests that most women book at a time when the effect of syphilis on the fetus would not have occurred bearing in mind that late detection of syphilis would have little effect on the overall outcome of the pregnancy. Early booking and screening is essential in preventing congenital syphilis. A community-based approach with continuous adequate screening and treatment would be indispensable. Thus, another argument to support the antenatal practice of screening for syphilis is that syphilis is capable of re-emerging in populations extremely rapidly when prevention efforts decline or collapse. ${ }^{27,28}$

However, could it be that the low rates of syphilis in our environment are due to early diagnosis and treatment based on cheaper and comprehensive screening? The fact of low prevalence of syphilis among the subjects in the three hospitals studied may not be strong enough to justify discontinuation of routine VDRL test among pregnant women.

The context that lots of resources are wasted in unnecessary treatment due to absence of an acceptable confirmatory test for syphilis and the very high false-positive result in VDRL testing may not justify discontinuation either. A previous study on VDRL screening in Nigeria by Mbamara and Obiechina ${ }^{25}$ argued that as far as the treatment of syphilis is effective, safe, and cost-effective as well as that there is no way to predict those that will be confirmed and the test is both expensive and not readily available, the approach of treating patients based only on VDRL-positive result is noble. Mbamara and Obiechina ${ }^{25}$ in their report supported that such treatment will reduce the risk of loss to follow-up on the premise of disinclination to travel long distance in order to obtain a confirmatory test, especially those who could not afford the cost of both the confirmatory test and treatment. They also posited that benzathine penicillin is effective and safe throughout pregnancy and that it should be liberally used. ${ }^{25}$

On the contrary, because of the increase in the demand for evidence-based medicine and increase in litigation encountered in medical practice, we may advocate that confirmatory test for syphilis is introduced in routine antenatal testing to reduce the problem of false positives. ${ }^{29}$ The adverse effect of the use of benzathine penicillin has been reported. Such adverse effects are of special interest to health care administrators and World Health Organization. ${ }^{30}$ The best prevention against such an increase in avoidable adverse effects of penicillins is the restriction of the unnecessary use of penicillin. Additionally, the argument may be put differently. The body does not always produce antibodies specifically in response to the syphilis bacteria. So, this screening test is not always ideal. The operative risks and economic involvement when 
added may push up arguments against routine VDRL or rapid plasma reagin testing in antenatal women. The risks involved in phlobotomy, exposure to blood-borne infections and other hazards are some of these operative risks. The total cost of routine VDRL screening of all antenatal patients may constitute a big burden to the health insurance where there is only about $5 \%$ coverage among the general population by the National Health Insurance Scheme. ${ }^{16,17}$

Limitations of the present analysis also need to be addressed. A main weakness is that despite the multisite design of the study, it is retrospective in nature and therefore some data would have been missed. Although this study is multicenter in design, our study did not claim to represent all the hospitals in south-east Nigeria. The selected hospitals a federal, a state, and a private hospital may not be true representatives of the health facilities in the state or the nation and so generalizations cannot be made based on findings from these three sites alone. There can be clusters of this disease in some places due to some public health peculiarities in such places.

\section{Conclusion}

In conclusion, while the prevalence of syphilis is extremely low in the antenatal care population at the three specialist care hospitals in south-east Nigeria, false-positive rate is high and prevalence did not significantly vary with maternal age or parity. Because syphilis is still a serious but preventable and curable disease, screening with VDRL alone without confirmatory tests may not be justified. Because of the increase in the demand for evidence-based medicine and litigation encountered in medical practice, we may advocate that confirmatory test for syphilis is introduced in routine antenatal testing to reduce the problem of false positives. The government should increase the health budget to include free routine antenatal testing, including TPHA, rather than recommend the rechanneling of resources meant for the screening and treatment of syphilis to other diseases, such as hepatitis B and C, considered more important.

\section{Author contributions}

All authors contributed to the study's design. GUE, ALO, and BON wrote the first draft, and IFA, CNA, CCE, and $\mathrm{COO}$ advised on the analysis. All authors contributed to the discussion and conclusion. Also, all authors have contributed significantly and are in agreement with the content of the manuscript.

\section{Disclosure}

The authors report no conflicts of interest in this work.

\section{References}

1. Frickmann H, Schwarz NG, Girmann M, et al. Serological survey of HIV and syphilis in pregnant women in Madagascar. Trop Med Int Health. 2013;18:35-39.

2. Binnicker MJ. Which algorithm should be used to screen for syphilis? Curr Opin Infect Dis. 2012;25:79-85.

3. Taiwo SS, Adesiji YO, Adekanle DA. Screening for syphilis during pregnancy in Nigeria: a practice that must continue. Sex Transm Infect. 2007;83:357-358.

4. Stray-Pederson B. Economic evaluation of maternal screening to prevent congenital syphilis. Sex Transm Dis. 1983;10:167-172.

5. Osoba AO. Serological test for syphilis among hospital patients in Ibadan, 1968-1970. Proceedings of the first medical research seminar, Fifty years of medical research in Nigeria, 1-4 February 1972. Yaba, Lagos: Academic Press; 1972:49-52.

6. Ekele BA, Bello CSS. Sero-reactivity amongst pregnant women screened for syphilis at Jos University Teaching Hospital. Niger J Med. 1997;6:11-13.

7. Bukar M, Audu BM, Takai UI, Ajayi BB, Kullima AA. Is routine antenatal screening for syphilis in Nigeria still justified clinically and economically? Saudi Med J. 2009;30:1311-1315.

8. Hira S, Ratnam A, Bhat G, et al. Congenital syphilis in Lusaka-II. Incidence at birth and potential risks among hospital delivered infants. East Afr Med J. 1982;59:306-308.

9. Azeze B, Fantahun M, Kidan KG, Haile T. Seroprevalence of syphilis among pregnant women attending antenatal clinics in a rural hospital in north west Ethiopia. Genitourin Med. 1995;71:347-350.

10. Hira SK, Bhat GJ, Chikamata DM. Syphilis intervention in pregnancy: Zambian demonstration project. Genitourin Med. 1990;66:159-164.

11. Skarpaas T, Loe K. The occurrence of positive serological syphilis reactions in pregnant women in Norway 1964-1978. Tidsskr Nor Laegeforen. 1980;100:1840-1843.

12. Klass P, Brown E, Pelton S. The incidence of prenatal syphilis at the Boston City Hospital: a comparison across four decades. Paediatrics. 1994;94:24-28.

13. Britwum-Nyarko A. Antenatal syphilis screening: policy versus practice in the Ashanti region, MSc Thesis, Department of Community Health, Kwame Nkrumah University of Science and Technology, Kumasi, Ghana, 2008.

14. WHO. The Global Elimination of Congenital Syphilis: Rational and Strategy for Action. World Health Organization; 2007. Available from: http://whqlibdoc.who.int/publications/2007/9789241595858_eng.pdf. Accessed June 5, 2014.

15. WHO/TDR Sexually Transmitted Diseases Diagnostics Initiative. Evaluation of rapid diagnostic tests: syphilis. Nat Rev Microbiol. 2006;4(Suppl 12):S33-S40.

16. Ilesanmi OS, Adebiyi AO, Fatiregun AA. National Health Insurance Scheme: how protected are households in Oyo State, Nigeria from catastrophic health expenditure? Int J Health Policy Manag. 2014;2: $175-180$.

17. National Health Insurance Scheme (NHIS). Road map for the implementation of Community-based health insurance scheme in Nigeria. Consultation on Support to NHIS CBSHIS roll-out in Programme States. Abuja: PPRINN-MNCH/NHIS; 2011.

18. Gharoro EP, Abedi HO. Routine antenatal screening for syphilis: useful or useless? The Benin experience. Trop J Obstet Gynaecol. 1999;16(1): 33-35.

19. Udigwe GO, Obiechina NJA, Ikechebelu JI, Udigwe IB. Venereal disease research laboratory test in pregnancy: is it time to stop screening? Trop J Med Res. 2001;5(2):31-35.

20. Olubukola A, Adesina O. Routine antenatal syphilis screening in south west Nigeria - a questionable practice. Ann Ib Postgrad Med. 2010;8: 16-19.

21. Ikeme AC, Okeke TC. The prevalence of VDRL as routine test for pregnant women: a critical study. Niger J Clin Pract. 2006;9:65-67.

22. Yakasai IA, Umar U, Ibrahim SA, Abubakar IS. Is routine antenatal screening test for syphilis using VDRL still relevant? Acad Res Int. 2012;2:151-155. 
23. Adeleke MA,Adebimpe WO, Sam-Wobo SO, Wahab AA, Akinyosoye LS, Adelowo TO. Sero-prevalence of malaria, hepatitis $b$ and syphilis among pregnant women in Osogbo, Southwestern Nigeria. J Infect Dis Immun. 2013;5:13-17.

24. Federal Ministry of Health. Technical Report on 2003 National HIV/ Syphilis Sentinel Survey Among Pregnant Women Attending Antenatal Clinics in Nigeria. Abuja. Nigeria: Federal Ministry of Health; 2004:125.

25. Mbamara SU, Obiechina NJA. Seroprevalence of venereal disease among pregnant women attending antenatal care (ANC) in Onitsha, Anambra State, south-east Nigeria. Niger J Med. 2011;20(1): $57-60$.
26. Egglestone SI, Turner AJ. Serological diagnosis of syphilis. PHLS Syphilis Serology Working Group. Common Dis Public Health. 2000;3: $158-162$.

27. Obisesan KA, Ahmed Y. Routine antenatal syphilis screening- a case against. Afr J Med Med Sci. 1999;28:185-187.

28. Wiwanitkit V. Screening for syphilis in pregnancy: which is the proper method? Arch Gynecol Obstet. 2007;276:629-631.

29. Domingues AP, Moura P, Vieira DN. Lessons from a decade of technical-scientific opinions in obstetrical litigation. J Forensic Leg Med. 2014;25:91-94.

30. Gutthe T, Idsoe O, Willcox RR. Untoward penicillin reactions. Bull World Health Organ. 1958;19(3):427-501.

\section{Publish your work in this journal}

The International Journal of Women's Health is an international, peerreviewed open-access journal publishing original research, reports, editorials, reviews and commentaries on all aspects of women's healthcare including gynecology, obstetrics, and breast cancer. The manuscript management system is completely online and includes a very quick and fair peer-review system, which is all easy to use. Visit http://www.dovepress.com/testimonials.php to read real quotes from published authors.

Submit your manuscript here: http://www.dovepress.com/international-journal-of-womens-health-journal 